SVN Neurology \section{prognosis after stroke in China: findings from a large nationwide stroke registry \\ Management characteristics and}

To cite: Qin $\mathrm{H}$, Chen $\mathrm{Y}$, Liu G, et al. Management characteristics and prognosis after stroke in China: findings from a large nationwide stroke registry. Stroke \& Vascular Neurology 2021;6: e000340. doi:10.1136/svn-2020-000340

- Additional material is published online only. To view please visit the journal online (http://dx.doi.org/10.1136/svn2020-000340).

$\mathrm{ZC}$ and $\mathrm{YW}$ are joint senior authors.

Received 30 January 2020 Revised 14 April 2020 Accepted 20 April 2020 Published Online First 22 June 2020

\section{Check for updates}

C Author(s) (or their employer(s)) 2021. Re-use permitted under CC BY-NC. No commercial re-use. See rights and permissions. Published by BMJ.

For numbered affiliations see end of article.

Correspondence to Dr Yongjun Wang; yongjunwang@ncrcnd.org.cn

\section{ABSTRACT}

Background and purpose There is limited nationwide evidence about the standard management characteristics of stroke types and prognosis in China. This study aimed to assess clinical characteristics, in-hospital and afterdischarge management characteristics and prognosis for stroke types in China.

Methods A nationwide registry recruited 14244 imagingconfirmed first-ever incident strokes from 132 hospitals across 31 provinces of China during 2007-2008, recording presenting characteristics, diagnostic procedures and inhospital treatment. After hospital discharge, patients were followed up for 6 months. Conventional statistical methods were used to examine the patterns of management and prognosis.

Results Overall, $68.7 \%, 26.9 \%$ and $4.4 \%$ were ischaemic stroke (IS), intracerebral haemorrhage (ICH), and subarachnoid haemorrhage (SAH), respectively. Only $20 \%$ were managed in a dedicated stroke unit. Among IS, $1.3 \%$ received thrombolysis within 3 hours after symptom onset, whereas the proportions of receiving in-hospital antiplatelet therapy, neuroprotective agents and traditional Chinese medicines (TCM) were $88.4 \%, 69.7 \%$ and $70.6 \%$, respectively. For ICH, $63.3 \%$ and $36.3 \%$ received neuroprotective agents and TCM in hospital, respectively. At discharge, $70.7 \%$ and $38.0 \%$ of the patients with IS were given antiplatelet and statin therapies, respectively, decreasing to $64.8 \%$ and $23.9 \%$, respectively, at 6 months In-hospital mortality was $3.2 \%, 9.3 \%$ and $10.1 \%$ for IS, $\mathrm{ICH}$ and SAH, respectively, with a further $8.6 \%, 18.2 \%$ and $22.0 \%$, respectively, died by 6 month. Meanwhile, inhospital recurrence rate was $2.6 \%, 1.9 \%$ and $7.2 \%$ for IS, $\mathrm{ICH}$ and SAH, respectively, with a further $8.0 \%, 5.1 \%$ and $7.5 \%$, respectively, recurred by 6 month.

Conclusions In China, the mortality rate of stroke is lower than that reported from west populations, though most strokes are not managed in specialised stroke unit. There is widespread use of some unproven therapies but limited proven treatments, especially after discharge, leading to unnecessary recurrent risks.

\section{INTRODUCTION}

Stroke is the second leading cause of death globally, with about three-quarters of the global burden of stroke deaths ( 6.5 million) and associated disability-adjusted life years (113million) lost now occurring in low-income and middle-income countries, particularly China where stroke rates are much higher than in most western countries, causing $>1$ million deaths each year. ${ }^{12}$ Compared with western countries, the proportion of stroke due to intracerebral haemorrhage (ICH) was greater in China and there are large and unexplained geographical variations in the age-standardised disease rates of stroke subtypes. ${ }^{34}$

Stroke also accounts for major medical and financial burden, ${ }^{5}$ including $2 \%-4 \%$ of total healthcare costs globally and $>4 \%$ of direct healthcare costs in industrialised countries. In China, the average cost of hospitalisation in 2006 was $¥ 11216$ ( $\approx$ US\$1602) per patient. ${ }^{6}$ Evidence-based guidelines for the management of stroke have been advocated in China, but there is still wide variation in their application by regions and by hospitals. ${ }^{7}$ While management and prognosis of patients who had a stroke have been extensively studied in western countries, ${ }^{8-10}$ there is little nationwide evidence in China, with previous studies in China constrained by small sample sizes, restricted to specific regions or lack of longterm follow-up data. ${ }^{11-15}$

To help fill the evidence gap, we present the data from the China National Stroke Registry (CNSR) involving 14000 imaging-confirmed strokes recruited from 31 provinces across China. We aimed to assess (1) overall standard of short-term and long-term management of main stroke types (ie, ischaemic stroke (IS) and ICH); and (2) case-fatality and long-term prognosis following discharge and the likely determinants.

\section{METHODS}

\section{Study design}

Detailed information about the CNSR's rationale, design and procedures has been previously published. ${ }^{16}$ Briefly, the CNSR was a nationwide hospital-based prospective registry 
study of patients who had stroke and transient ischaemic attacks (TIA) aged over 18 years. CNSR was established during September 2007 and August 2008 involving 132 hospitals (100 tier III and 32 tier II) from all over China including 27 provinces and 4 municipalities. The selection of hospital was determined by CNSR steering committee according to various criteria, including available facility (eg, CT or MRI) for diagnosing stroke types. Written informed consent was obtained from all patients or their legal representatives.

\section{Eligibility criteria}

The eligibility criteria for enrolment of patients into the study included: (1) age 18 years or older; (2) diagnosis at hospital admission of acute first-ever stroke including IS, $\mathrm{ICH}$ and subarachnoid haemorrhage (SAH) according to WHO criteria; (3) stroke confirmed by brain CT or MRI.

Of the 39741 cases screened for eligibility, 17525 $(44.1 \%)$ were excluded for time since onset $>14$ days $(51.2 \%)$, diagnosis of condition other than stroke or TIA $(22.8 \%)$, refuse of participation $(15.9 \%)$, died before enrolment (7.8\%) and other reasons (2.4\%; figure 1), and 22261 were diagnosed as acute stroke, of whom 1387 were TIA and a further 6490 had a history of stroke, leaving 14 339 eligible cases. For the present studies, 95 individuals with strokes of an unspecified type were excluded leaving 14244 cases for the main analyses (figure 1).

\section{Data collection}

In each hospital, trained health professionals identified patients through reviewing medical records. Eligible participants, or their immediate relatives, were then interviewed for their consent and relevant clinical information in the medical notes was recorded in the standardised questionnaire. All the collected data were transmitted on a regular basis to study coordinating centre in Beijing. After hospital discharge, trained health professionals at Beijing Tiantan Hospital interviewed the participants who were discharged alive using a structured telephone interview at 3 and 6 months after onset. ${ }^{16}$ Main outcome measures were all-cause mortality and major vascular events (MVE, vascular death, recurrent stroke or myocardial infarction).

\section{Statistical analysis}

All analyses were conducted separately for three main strokes types (IS, ICH and SAH). Data were reported mean values and SD for continuous variables, and median with IQR for nominal variables of patients. Percentages were used for categorical parameters. Except indicated in the tables, missing values were distributed to each category according to proportion of non-missing data. The number and proportion of missing data for these variables were shown as following: smoking history (531, 3.7\%), National Institutes of Health Stroke Scale (NIHSS) at admission $(738,5.2 \%)$ and others (eg, education, alcohol history $<3 \%$ ). All analyses were performed using SAS software V.9.3 (SAS Institute).
RESULTS

\section{Patient characteristics}

Of the 14244 strokes included, the mean (SD) age was 62.5 (13.3) years, $60.6 \%$ were men, $68.7 \%$ were IS, $26.9 \%$ ICH and $4.4 \%$ SAH (figure 1). Patients with IS were older, had higher body mass index and were more likely to have prior cardiovascular disease, diabetes or hyperlipidaemia, while patients with ICH were more likely to have hypertension and SAH cases tended to be younger, and were more likely to be female and have a lower prevalence of hypertension. There was lower prevalence of smoking and alcohol consumption in SAH, but little difference in access to health insurance across three stroke types. There were higher proportion of SAH cases in the top tier hospitals but no significant difference in distribution of hospital ranks between IS and ICH (table 1). Prior to their first hospital admission, over one-third of patients with IS (39.6\%) and ICH (36.9\%) were taking antihypertensive treatments, significantly higher than that of SAH $(23.2 \%)$. The use of lipid-lowering medications was, however, extremely low $(1.8 \%)$ in IS.

\section{Severity and use of acute treatments on admission}

Overall, less than half $(48.7 \%)$ of all stroke cases were admitted to hospital within 12 hours of symptoms onset, with the proportion varying by types (42\% IS, $66 \%$ ICH and $55 \%$ SAH: table 2). Only about a quarter $(23.0 \%)$ were transferred by ambulance (18.5\% IS, $32.8 \%$ ICH, $33.4 \% \mathrm{SAH})$. At admission, mean blood pressure was 154/90 mm Hg overall, highest for ICH $(164 / 96 \mathrm{~mm} \mathrm{Hg})$, followed by IS $(151 / 88 \mathrm{~mm} \mathrm{Hg})$ and SAH $(146 / 86 \mathrm{~mm}$ $\mathrm{Hg}$ ).

Most patients were assessed for severity at admission. Patients with ICH had a higher proportion with NIHSS scale $\geq 15$ cases $(28.2 \%)$ and Glasgow Coma Scale 3-5 cases $(6.8 \%)$ than those with SAH $(10.5 \%$ and $4.5 \%$, respectively) and IS $(10.9 \%$ and $1.2 \%$, respectively) (table 2). Of the patients with IS, $17 \%$ were admitted to hospital within 3 hours of symptom onset, among whom only $1.3 \%$ received recombinant tissue plasminogen activator (r-tPA) therapy, with similar proportion in tier III $(1.3 \%)$ and tier II hospitals $(1.2 \%)$.

\section{Management and treatment during and after hospitalisation}

Overall, only one in five stroke cases was treated in stroke units. The mean hospital stay among survivors was 18 days, longest for ICH (21 days). Apart from CT or MRI, the most frequent used investigation for IS was cervical ultrasound $(43 \%)$, followed by transcranial Doppler $(31 \%)$ and cerebral CT angiography (CTA)/magnetic resonance angiogram (MRA; 30\%). For ICH, 29\% and $31 \%$ had 24 hours blood pressure and ECG (Holter) monitoring, respectively. Almost half of SAH cases had digital subtraction angiography (48\%) and over onethird had both Holter and blood pressure monitoring. Carotid endarterectomy and stenting were hardly used at all in patients with IS $(0.1 \%$ and $0.5 \%$, respectively). In 


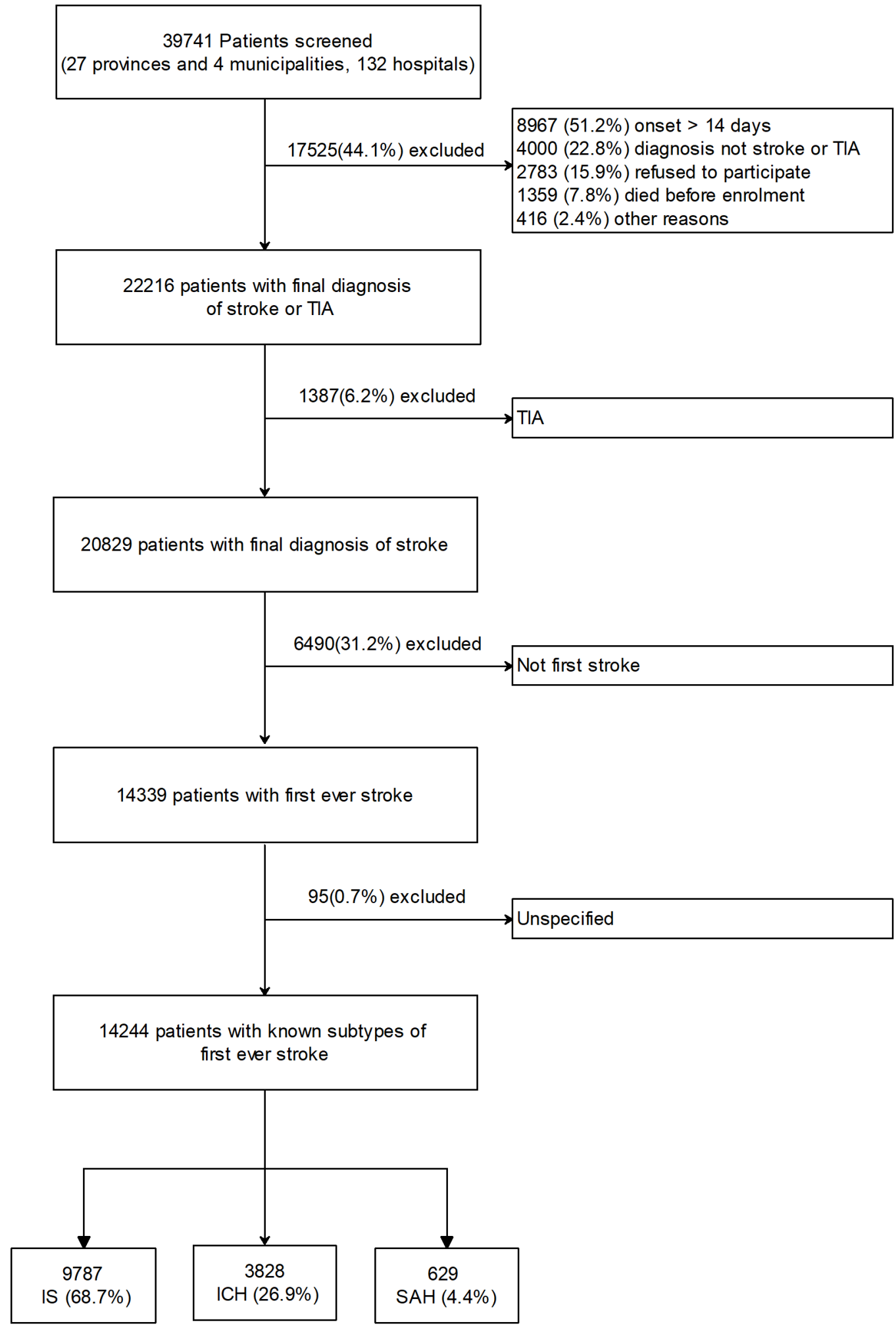

Abbreviations: IS, ischaemic stroke; ICH, intracerebral haemorrhage; SAH, subarachnoid haemorrhage.

Figure 1 Flow diagram for the enrolment process of the potentially eligible patients in the China National Stroke Registry. TIA, transient ischaemic attacks.

contrast, coiling and craniotomy were used in $16 \%$ and $10 \%$ of patients with $\mathrm{SAH}$, respectively (table 3 ).

Neuroprotective agents were widely used during hospitalisation, irrespective of stroke types $(70 \%$ in IS,
63\% ICH and 59\% SAH). Likewise, traditional Chinese medicines (TCM) was used widely, in those with IS $(71 \%$ IS, 36\% ICH and 20\% SAH). For both ICH and SAH, osmotic diuretics (mainly mannitol) were used in over 
Table 1 Baseline characteristics of China National Stroke Registry patients by stroke type

\begin{tabular}{|c|c|c|c|c|}
\hline & $\begin{array}{c}\text { Total } \\
(\mathrm{n}=14244)\end{array}$ & $\begin{array}{c}\text { IS } \\
(n=9787)\end{array}$ & $\begin{array}{c}\begin{array}{c}\mathrm{ICH} \\
(\mathrm{n}=3828)\end{array} \\
\end{array}$ & $\begin{array}{c}\text { SAH } \\
(n=629)\end{array}$ \\
\hline \multicolumn{5}{|l|}{ Age (years; \%) } \\
\hline$<45$ & 11.1 & 8.7 & 15.5 & 21.8 \\
\hline $46-55$ & 20.3 & 18.3 & 23.8 & 29.7 \\
\hline $56-65$ & 24.6 & 24.6 & 24.7 & 25.1 \\
\hline $66-75$ & 26.0 & 28.1 & 22.2 & 16.5 \\
\hline$>75$ & 18.0 & 20.4 & 13.8 & 6.8 \\
\hline Mean (SD) & $62.5(13.3)$ & $64.0(13.0)$ & $59.9(13.6)$ & $55.9(12.8)$ \\
\hline \multicolumn{5}{|l|}{ Gender (\%) } \\
\hline Male & 60.6 & 61.2 & 61.7 & 43.1 \\
\hline \multicolumn{5}{|l|}{ Education (\%) } \\
\hline Elementary or below & 45.3 & 44.8 & 47.1 & 42.9 \\
\hline Middle school & 27.1 & 26.3 & 28.5 & 30.5 \\
\hline High school or above & 27.6 & 28.9 & 24.4 & 26.6 \\
\hline Health insurance (\%) & 76.4 & 78.1 & 72.9 & 70.9 \\
\hline \multicolumn{5}{|l|}{ Smoking (\%) } \\
\hline Never & 60.1 & 59.3 & 60.5 & 69.2 \\
\hline Ex & 10.3 & 10.6 & 10.5 & 5.2 \\
\hline Current & 29.6 & 30.1 & 29.0 & 25.6 \\
\hline \multicolumn{5}{|l|}{ Alcohol (\%) } \\
\hline Never & 66.1 & 66.7 & 63.5 & 72.4 \\
\hline Ex & 3.0 & 3.4 & 2.3 & 0.8 \\
\hline Current & 31.0 & 30.0 & 34.3 & 26.8 \\
\hline \multicolumn{5}{|l|}{$\operatorname{BMI}\left(\mathrm{kg} / \mathrm{m}^{2}\right)^{\star}(\%)$} \\
\hline$<18.5$ & 3.7 & 3.3 & 4.7 & 4.3 \\
\hline $18.6-24.9$ & 51.1 & 50.6 & 52.2 & 52.2 \\
\hline $25.0-29.9$ & 28.1 & 29.2 & 26.4 & 22.3 \\
\hline$\geq 30$ & 4.8 & 4.8 & 4.9 & 3.8 \\
\hline Unknown & 12.3 & 12.2 & 11.8 & 17.5 \\
\hline \multicolumn{5}{|l|}{ Prior disease history (\%) } \\
\hline Hypertension & 57.9 & 57.2 & 62.7 & 39.9 \\
\hline Diabetes mellitus & 14.8 & 18.3 & 7.3 & 6.7 \\
\hline Hyperlipidaemia & 7.3 & 8.3 & 5.2 & 4.8 \\
\hline TIA & 1.5 & 2.1 & 0.4 & 0.5 \\
\hline Cardiovascular diseases & 14.3 & 17.8 & 6.9 & 5.1 \\
\hline \multicolumn{5}{|l|}{ Hospital rank (\%) } \\
\hline Tier III & 77.2 & 77.8 & 74.3 & 83.6 \\
\hline Tier II & 22.8 & 22.2 & 25.7 & 16.4 \\
\hline \multicolumn{5}{|l|}{ Medication before admission (\%) } \\
\hline Antithrombotics & 8.6 & 10.2 & 5.1 & 5.3 \\
\hline Antihypertensive medicines & 38.1 & 39.6 & 36.9 & 23.2 \\
\hline Diabetes medicines & 11.0 & 13.9 & 4.6 & 4.1 \\
\hline Lipid-lowing medicines & 1.4 & 1.8 & 0.6 & 0.6 \\
\hline
\end{tabular}

*Measured or self-reported.

$\mathrm{BMI}$, body mass index; ICH, intracerebral haemorrhage; IS, ischaemic stroke; SAH, subarachnoid haemorrhage; TIA, transient ischaemic attacks. 
Table 2 Presenting characteristics, examination and acute treatment at admission by stroke type

\begin{tabular}{|c|c|c|c|c|}
\hline & Total & IS & ICH & SAH \\
\hline & $(n=14244)$ & $(n=9787)$ & $(n=3828)$ & $(n=629)$ \\
\hline \multicolumn{5}{|l|}{ NIHSS (\%) } \\
\hline $0-3$ & 35.7 & 38.3 & 23.9 & 67.7 \\
\hline $4-7$ & 23.9 & 27.7 & 16.9 & 6.7 \\
\hline $8-14$ & 19.8 & 18.7 & 25.2 & 4.0 \\
\hline $15-21$ & 8.3 & 6.8 & 13.3 & 2.4 \\
\hline$\geq 22$ & 7.2 & 4.1 & 14.9 & 8.1 \\
\hline Unknown & 5.2 & 4.6 & 5.8 & 11.1 \\
\hline $\begin{array}{l}\text { Median (25th- } \\
75 \text { th) }{ }^{*}\end{array}$ & $5(2-10)$ & $4(2-9)$ & $9(3-16)$ & $0(0-2)$ \\
\hline \multicolumn{5}{|l|}{ GCS (\%) } \\
\hline $3-5$ & 2.9 & 1.2 & 6.8 & 4.5 \\
\hline $6-10$ & 9.2 & 6.8 & 15.5 & 7.8 \\
\hline $11-15$ & 86.6 & 90.5 & 76.5 & 87.0 \\
\hline \multicolumn{5}{|l|}{$\begin{array}{l}\text { Blood pressure } \\
(\mathrm{mm} \mathrm{Hg})\end{array}$} \\
\hline Mean SBP (SD) & $154.4(26.2)$ & $151.0(24.3)$ & $164.3(28.1)$ & 146.3 \\
\hline Mean DBP (SD) & $90.1(15.7)$ & $87.9(14.1)$ & $96.3(17.7)$ & $86.4(15.0)$ \\
\hline \multicolumn{5}{|l|}{$\begin{array}{l}\text { Hours since } \\
\text { symptom onset } \\
\text { (\%) }\end{array}$} \\
\hline$\leq 3$ & 21.7 & 16.6 & 34.3 & 24.9 \\
\hline$\sim 6$ & 14.4 & 12.0 & 19.9 & 17.5 \\
\hline$\sim 12$ & 12.8 & 13.0 & 12.2 & 12.8 \\
\hline$>12$ & 51.3 & 58.4 & 33.7 & 44.8 \\
\hline $\begin{array}{l}\text { Transport by } \\
\text { Ambulance (\%) }\end{array}$ & 23.0 & 18.5 & 32.8 & 33.4 \\
\hline \multicolumn{5}{|c|}{$\begin{array}{l}\text { First neuroimaging } \\
\text { test (\%) }\end{array}$} \\
\hline CT & 92.4 & 89.3 & 98.7 & 98.5 \\
\hline MR & 7.6 & 10.7 & 1.3 & 1.5 \\
\hline r-tPA given (\%) & - & 1.3 & - & - \\
\hline
\end{tabular}

*Unknown data were excluded.

DBP, diastolic blood pressure; GCS, Glasgow Coma Scale; ICH, intracerebral

haemorrhage; IS, ischaemic stroke; NIHSS, National Institutes of Health Stroke Scale; r-tPA, recombinant tissue plasminogen activator; $\mathrm{SAH}$, subarachnoid haemorrhage SBD, systolic blood pressure.

$90 \%$ of patients (table 3 ). Overall, almost half $(48 \%)$ of all patients were treated with antihypertensive medicine during hospitalisation (table 3 ), with $63 \%$ of the treatment involving a single agent, mainly calcium antagonists $(31 \%)$ and ACE inhibitors (22\%). At discharge, the use of antihypertensive agents was highest for ICH (51\%), followed by IS (39\%) and SAH (18\%). At 6 months after stroke onset, the use of antihypertensive medication had no significant differences in absolute term for ICH $(58 \%)$, IS (43\%) and SAH (32\%; figure $2 \mathrm{~A})$.

Antiplatelet therapy was used in $88 \%$ of patients with IS during hospitalisation, then decreased gradually to $65 \%$ at 6 months. The proportions who used aspirin alone, clopidogrel alone or combined aspirin and clopidogrel during hospitalisation were $67 \%, 10 \%$ and $8 \%$, respectively. Anticoagulant medication (mainly warfarin) was used only in $1.5 \%$ of patients with IS at discharge. Statins were used in $46 \%$ of patients with IS during hospitalisation, which decreased to $24 \%$ at 6 months (figure $2 \mathrm{~B}$ ).

\section{Prognosis after stroke onset during and after hospitalisation}

After hospital admission, the case fatality was the highest for SAH (10.1\%), followed by ICH (9.3\%) and IS $(3.2 \%)$. Similarly, $7.2 \%$ of SAH had recurrent stroke during hospitalisation, much higher than that of IS (2.6\%) and ICH $(1.9 \%)$. The most common in-hospital complication was pneumonia, particularly in those with ICH $(16.1 \%$; table 4$)$. At 6 months after onset, patients with $\mathrm{SAH}$ had the highest mortality $(22.0 \%)$, followed by ICH $(18.2 \%)$ and IS (8.6\%) (figure 3). However, patients with IS had the highest recurrent rate $(8.0 \%)$, followed by $\mathrm{SAH}$ $(7.5 \%)$ and ICH $(5.1 \%)$. For MVE, the event rates at 6 months were $16.5 \%, 23.1 \%$ and $28.4 \%$ for those with IS, $\mathrm{ICH}$ and SAH.

\section{DISCUSSION}

This is the first large nationwide stroke registry in China of the general management, treatments and prognosis during and after hospitalisation among patients admitted to hospital with first-ever incident stroke. It showed that the proportion of ICH was much greater in China than that in typical western populations, confirming previous reports from clinical and population-based studies. 17,18 For each of the three main types of stroke, the use of many proven effective management procedures (eg, stroke units) and treatments (eg, r-tPA, and lipid-lowering) was still inadequate. By contrast, many treatments with unproven efficacy, including particularly neuroprotective agents and TCM, were widely used. Moreover, the duration of hospital stay, though has reduced significantly compared with that seen 20 years ago, was still much longer than in western countries. ${ }^{9} 19$ Taken together, the present study provided direct nationwide evidence that management of stroke in China has much to improve in order to achieve evidence-based care and management. ${ }^{20}$

Several previous hospital-based and community-based studies have reported a higher proportion of haemorrhagic stroke in East Asian than in the western populations. ${ }^{1718}$ In typical Caucasian populations, $67.3 \%-80.5 \%$ of first ever strokes were classified as ischaemic, $6.5 \%-$ $19.6 \%$ as primary $\mathrm{ICH}, 0.8 \%-7.0 \%$ as $\mathrm{SAH}$ and $2.0 \%-$ $14.5 \%$ as undefined. ${ }^{10}$ Our nationwide study in China showed that of those admitted to hospital with acute stroke, over a quarter were imaging-confirmed ICH. Prior to this study, there were little data about use of vascular imaging which is crucial to establish reliably the stroke aetiology. In the National Acute Stroke Israeli Registry, use of CTA or MRA for further investigation of ischaemic events increased from $2.1 \%$ in 2004 to $7.9 \%$ in $2007 .{ }^{21}$ Our study demonstrates that the utilisation of these imaging modalities was $30 \%$ for CTA or MRA in China, especially in urban hospitals even though it is costly and may be associated with certain side effects. Further research works are needed to demonstrate the cost effectiveness 
Table 3 Patterns of in-hospital investigation, procedures and medications by stroke type

\begin{tabular}{|c|c|c|c|c|}
\hline & Total $^{*}$ & IS & $\mathrm{ICH}$ & SAH \\
\hline & $(n=13270)$ & $(n=9292)$ & $(n=3424)$ & $(n=554)$ \\
\hline \multicolumn{5}{|l|}{ Type of ward admitted (\%) } \\
\hline Stroke unit & 20.3 & 21.1 & 18.7 & 19.1 \\
\hline Neurosurgery ward & 2.1 & 0.5 & 4.0 & 16.1 \\
\hline ICU & 9.2 & 5.5 & 17.7 & 19.1 \\
\hline General medicine & 68.5 & 73.0 & 59.8 & 45.7 \\
\hline \multicolumn{5}{|c|}{ Length of stay among survivors (days; \%) } \\
\hline$\leq 3$ & 3.3 & 3.0 & 3.6 & 7.2 \\
\hline $4-14$ & 41.5 & 47.3 & 26.9 & 28.5 \\
\hline $15-28$ & 42.4 & 40.1 & 48.9 & 42.3 \\
\hline$>29$ & 12.0 & 9.0 & 19.5 & 18.2 \\
\hline Unknown & 0.9 & 0.6 & 1.1 & 3.8 \\
\hline Mean (SD) & $17.8(11.7)$ & $16.6(11.2)$ & $20.8(12.4)$ & $19.1(11.6)$ \\
\hline \multicolumn{5}{|l|}{ Specific investigation (\%) } \\
\hline 24 hours BP monitor & 20.3 & 16.2 & 28.5 & 36.6 \\
\hline Holter monitor & 22.9 & 18.5 & 31.3 & 43.3 \\
\hline Digital subtraction angiography & 5.6 & 4.1 & 2.6 & 47.5 \\
\hline Cervical ultrasound & 32.0 & 43.2 & 6.6 & 1.6 \\
\hline Transcranial Doppler & 23.6 & 31.2 & 5.3 & 8.5 \\
\hline Cervical CTA/MRA & 5.5 & 7.2 & 1.2 & 3.1 \\
\hline Cerebral CTA/MRA & 24.2 & 29.8 & 9.3 & 23.3 \\
\hline \multicolumn{5}{|l|}{ Surgery/procedure given (\%) } \\
\hline Carotid endarterectomy & - & 0.1 & - & - \\
\hline Stenting/angioplasty & - & 0.5 & - & - \\
\hline Craniotomy & 1.4 & 0.3 & 3.2 & 10.1 \\
\hline Coiling & - & - & - & 15.9 \\
\hline \multicolumn{5}{|l|}{ Medication (\%) } \\
\hline Any antiplatelet & - & 88.4 & - & - \\
\hline Anticoagulants & - & 24.2 & - & - \\
\hline Antihypertensive medicines & 47.9 & 43.0 & 62.0 & 43.9 \\
\hline Statins & 34.1 & 45.7 & 7.4 & 5.1 \\
\hline Dehydrant medicines & 47.3 & 28.1 & 92.0 & 92.1 \\
\hline Neuroprotective & 67.6 & 69.7 & 63.3 & 58.7 \\
\hline Traditional Chinese medicine & 59.7 & 70.6 & 36.3 & 20.4 \\
\hline
\end{tabular}

${ }^{*}$ Restricted to patients admitted to hospital ward.

BP, blood pressure; CTA, CT angiography; ICH, intracerebral haemorrhage; ICU, intensive care unit; IS, ischaemic stroke; MRA, magnetic resonance angiogram; $\mathrm{SAH}$, subarachnoid haemorrhage.

and safety of these investigations before their use can be adopted into routine practice.

Admission to a specialised stroke unit or an intensive care unit care unit is the key to safe and effective stroke care $^{22}$ and is recommended by current guidelines. ${ }^{23} 24$ In our study, only $20 \%$ of patients who had a stroke who admitted to top and medium rank of hospitals were treated in stroke unit, which is much lower than that about $59 \%-87 \%$ in most western countries. ${ }^{25}{ }^{26}$ The situation would be even worse in most rural and district hospitals where resources are limited and has not improved much over the last 10 years in many particular urban regions. ${ }^{27}$ Although stroke unit was first introduced into China in 2001, there is well-established evidence that it can significantly improve health outcome following stroke. ${ }^{28}$ Therefore, it is urgent and necessary to use certification or quality improvement systems to validate these stroke units in China.

On average, patients who had a stroke in China stayed for over 2 weeks in hospital, which is about twice as long 


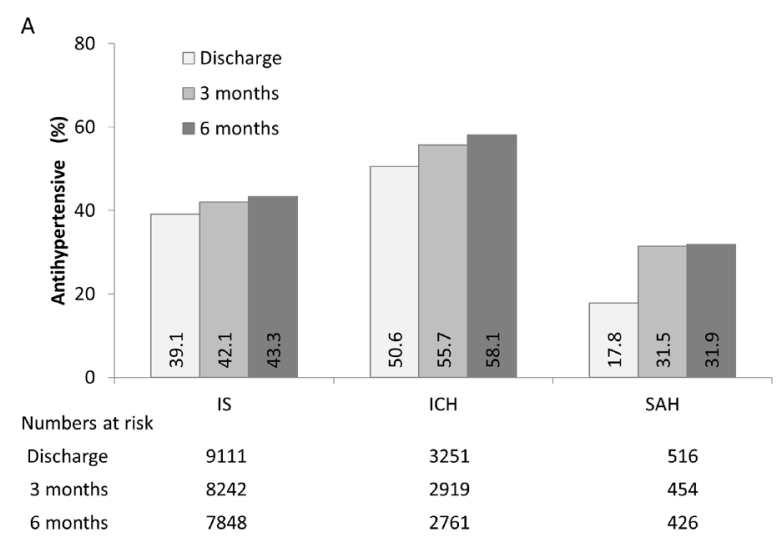

B

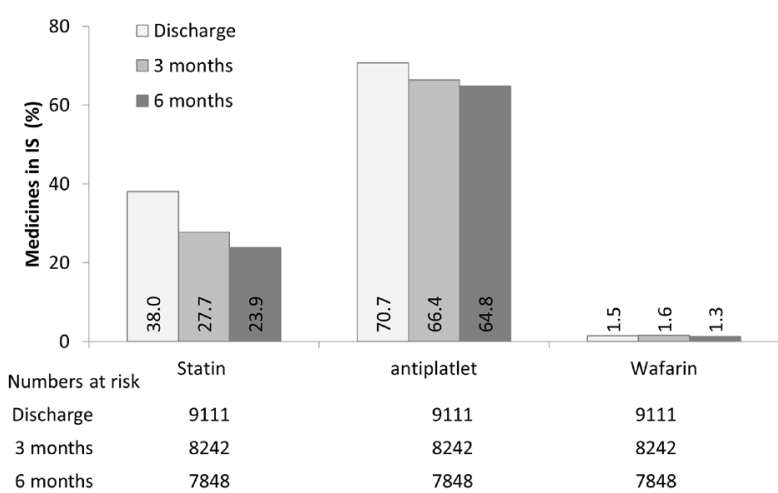

Abbreviations: IS, ischaemic stroke; ICH, intracerebral haemorrhage; SAH, subarachnoid haemorrhage.

Figure 2 (A) Long-term use of antihypertensive and (B) other secondary prevention treatments since onset, by stroke types.

as that in most western countries. ${ }^{99}{ }^{30}$ Increased lengths of stay incur greater financial and social costs on patients' families and, more broadly, the state. The reasons for longer hospital treatment for stroke in China may be attributed partly to the reimbursement policy that covers predominantly hospital treatments and partly to lack of rehabilitation facilities in the community for post-stroke cares.

The present study also assessed the adherence to clinical guideline-based performance measures of stroke. Thrombolysis using r-tPA therapy, which has been originally recommended to be administered within 3 hours after onset in national guidelines for treatment of acute IS since the late $1990 \mathrm{~s}$, was given only to $1.3 \%$ of potentially eligible patients with IS in China, much lower than $3.0 \%-8.5 \%$ in the USA. ${ }^{31}$ Despite substantial improvement during the past 10 years in China,${ }^{15}$ there is still a major gap in terms of quality of care between China and western countries. In the American Heart Association's Get With The Guideline registry study conducted in the same period, antiplatelet was used in $83.9 \%$ of patients at discharge, higher than that of $70.7 \%$ in our study. ${ }^{32}$ Similarly, the use of antihypertensive and lipid-lowering therapy was also much higher in USA than in China $(76.7 \%$ vs $39.1 \%$, and $74.5 \%$ vs $38.0 \%$, respectively). ${ }^{32}$ Furthermore, the use of all evidence-based treatments after discharge was much lower compared with that in the western countries, reflecting lack of adequate primary care system in China ${ }^{32}{ }^{33}$ With regards to secondary prevention of ICH or $\mathrm{SAH}$, antihypertensive treatment is the most important recommended therapy. ${ }^{34}$ However, just over half of ICH was given during hospitalisation and at 6 months. Despite suboptimal use of proven therapies for stroke treatment and secondary prevention, many unproven treatments were still widely used regardless of stroke types, in particular, the neuroprotective agents (eg, intravenous edaravone, ganglioside GM1, citicholine) and TCM (herbal/ complementary therapies) through whole hospital stay, which is consistent with previous reports, in China. ${ }^{35}$

Case fatality of stroke varies considerably between different ethnic and geographical populations. ${ }^{36}$ The observed mortality data in our study for IS at discharge $(3.2 \%)$ and at 6 months $(8.6 \%)$ were similar to that in previous report of Chinese populations, ${ }^{17}$ but much lower than $5.6 \%$ (at discharge $)^{37}$ and about $20 \% \quad(6$

Table 4 Proportion of patients with major outcomes in hospital by stroke type

\begin{tabular}{|c|c|c|c|c|}
\hline & Total* $^{\star}$ & IS & $\mathrm{ICH}$ & SAH \\
\hline Outcome & $(n=13368)$ & $(n=9314)$ & $(n=3497)$ & $(n=557)$ \\
\hline Mortality (\%) & 5.1 & 3.2 & 9.3 & 10.1 \\
\hline Myocardial infarction (\%) & 0.5 & 0.4 & 0.6 & 0.8 \\
\hline MVE†(\%) & 8.0 & 6.1 & 11.6 & 17.2 \\
\hline Deep vein thrombosis & 0.4 & 0.3 & 0.6 & 0.4 \\
\hline Pneumonia & 11.0 & 9.4 & 16.1 & 8.4 \\
\hline Gastrointestinal bleeding & 2.2 & 1.6 & 3.9 & 1.2 \\
\hline
\end{tabular}

Online supplementary appendix file: the China National Stroke Registry investigators.

*Restricted to patients hospitalised, including those died at emergency department.

†Major vascular event (MVE) is defined as any death, recurrent stroke or myocardial infarction.

$\mathrm{ICH}$, intracerebral haemorrhage; IS, ischaemic stroke; SAH, subarachnoid haemorrhage. 


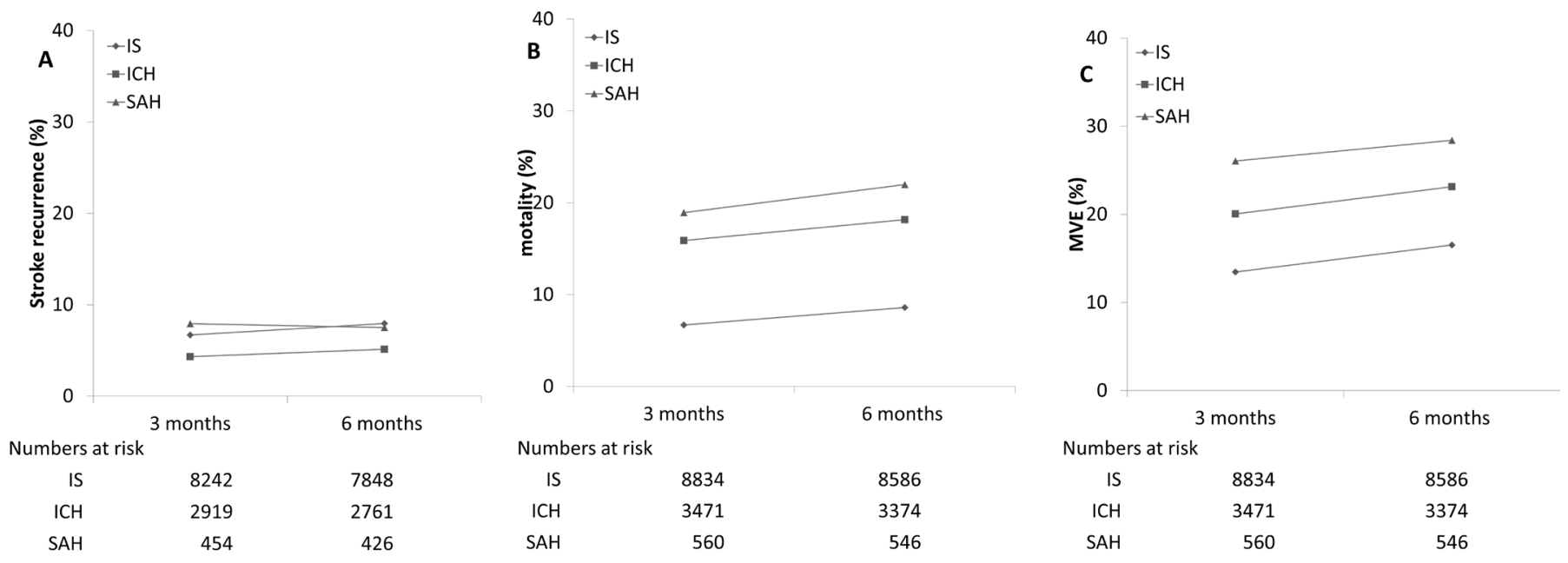

Abbreviations: IS, ischaemic stroke; ICH, intracerebral haemorrhage; $\mathrm{SAH}$, subarachnoid haemorrhage.

Figure 3 Event rates since onset of (A) recurrent stroke, (B) mortality and (C) major vascular event (MVE), by stroke types.

months $)^{38}$ recorded in the western countries. The mortality of ICH $(18.2 \%)$ at 6 months was also much lower than $39 \%$ typically reported in other studies of west populations. ${ }^{39}$ The lower mortality in the present study reflected mainly inclusion of less severe cases (median National Institutes of Health scores were 4 and 9, respectively, for IS and ICH; table 2). Despite this, $7.2 \%$ of surviving patients in our study had recurrent stroke in 6 months, which was greater than that $(5.0 \%)$ reported in western populations. ${ }^{40}$ The high recurrent risk in China reflected in part inadequate use of proven secondary preventive treatments.

Our study included mainly medium-sized or largesized urban hospitals, and these hospitals were not selected to be national representative. Moreover, many severe cases of stroke were not recruited, which would reduce the underlying mortality. Moreover, this study was conducted about 10 years ago and cannot thoroughly reflect the current state. Despite these limitations, the CNSR remains the largest registry covering all areas of China so far into treatments, secondary prevention and outcomes after stroke in China. Results from the present study provide detailed data to help assess the extent to which future quality improvements can be made as well as for reform of the health insurance system in China.

Some studies are tracking changes in quality of care and prognosis for hospitalised patients in China. ${ }^{20} 41$ Further studies, ideally using the stratified multistage probability sampling method, are needed to monitor the changing patterns of stroke care in China. It is also important to assess the efficacy and safety of widely used but unproven medications, especially neuroprotective agents and TCM, using large randomised clinical trials. Strategies to reduce length of hospital stay should be developed, thus increasing the cost effectiveness of hospital-based healthcare. Reform of the health insurance system especially in establishing community-based medicine to follow up major chronic diseases including stroke will be critically important in achieving these aims.

Author affiliations

${ }^{1}$ Department of Neurology, Beijing Tiantan Hospital, Capital Medical University,

Beijing, China

${ }^{2}$ China National Clinical Research Center for Neurological Diseases, Beijing, China

${ }^{3}$ Center of Stroke, Beijing Institute for Brain Disorders, Beijing, China

${ }^{4}$ Beijing Key Laboratory of Translational Medicine for Cerebrovascular Disease, Beijing, China

${ }^{5}$ Medical Research Council Population Health Research Unit, Nuffield Department of Population Health, University of Oxford, Oxford, UK

${ }^{6}$ Clinical Trial Service Unit \& Epidemiological Studies Unit, Nuffield Department of Population Health, University of Oxford, Oxford, UK

\section{Twitter Yilong Wang @yilong}

Acknowledgements The authors appreciate the multiple contributions made by participating investigators (see appendix). They appreciate the writing advice by Christopher Roma-Agvanian, and statistical advice by Lu Ling.

Contributors YW, LL, XZ and YW designed the study. ZC conceived of this article. $\mathrm{HQ}$ drafted the article, with further contributions from YC, IT and ZC. HQ, RZ and GL managed and analysed the data. All authors interpreted data and approved the final version of the article.

Funding National Key R\&D Plan of the Ministry of Science and Technology of China (2016YFC1301604, 2017YFC1307702); National Natural Science Foundation of China (81870907); Ministry of Science and Technology and the Ministry of Health of China (2006BA101A11 and 2009CB521905); Beijing Municipal Administration of Hospitals' Mission Plan (SML20150502).

Competing interests None declared.

Patient consent for publication Not required.

Ethics approval The study was approved by the Central Ethics Committee at Beijing Tiantan Hospital affiliated to Capital Medical University.

Provenance and peer review Not commissioned; externally peer reviewed. Data availability statement Data are available upon reasonable request. Data may be obtained from a third party and are not publicly available. None.

Open access This is an open access article distributed in accordance with the Creative Commons Attribution Non Commercial (CC BY-NC 4.0) license, which permits others to distribute, remix, adapt, build upon this work non-commercially, and license their derivative works on different terms, provided the original work is properly cited, appropriate credit is given, any changes made indicated, and the use is non-commercial. See: http://creativecommons.org/licenses/by-nc/4.0/. 


\section{ORCID iDs}

Haiqiang Qin http://orcid.org/0000-0003-4500-7508

Gaifen Liu http://orcid.org/0000-0002-7038-3444

Runhua Zhang http://orcid.org/0000-0003-4825-191X

Zixiao Li http://orcid.org/0000-0002-4713-5418

Yongjun Wang http://orcid.org/0000-0002-9976-2341

\section{REFERENCES}

1 Feigin VL, Krishnamurthi RV, Parmar P, et al. Update on the global burden of ischemic and hemorrhagic stroke in 1990-2013: the GBD 2013 study. Neuroepidemiology 2015;45:161-76.

2 Wang W, Jiang B, Sun H, et al. Prevalence, Incidence, and Mortality of Stroke in China: Results from a Nationwide Population-Based Survey of 480687 Adults. Circulation 2017;135:759-71.

3 Wu Z, Yao C, Zhao D, et al. Sino-MONICA project: a collaborative study on trends and determinants in cardiovascular diseases in China, part I: morbidity and mortality monitoring. Circulation 2001;103:462-8.

4 Zhou M, Wang H, Zhu J, et al. Cause-Specific mortality for 240 causes in China during 1990-2013: a systematic subnational analysis for the global burden of disease study 2013. Lancet 2016;387:251-72.

5 Johnston SC, Mendis S, Mathers CD. Global variation in stroke burden and mortality: estimates from monitoring, surveillance, and modelling. Lancet Neurol 2009;8:345-54.

6 Wei JW, Heeley EL, Jan S, et al. Variations and determinants of hospital costs for acute stroke in China. PLoS One 2010;5. doi:10.1371/journal.pone.0013041. [Epub ahead of print: $28 \mathrm{Sep}$ 2010].

7 Wu S, Wu B, Liu M, et al. Stroke in China: advances and challenges in epidemiology, prevention, and management. Lancet Neurol 2019;18:394-405.

8 Bangalore S, Schwamm L, Smith EE, et al. Secondary prevention after ischemic stroke or transient ischemic attack. Am J Med 2014;127:728-38.

9 Fonarow GC, Reeves MJ, Smith EE, et al. Characteristics, performance measures, and in-hospital outcomes of the first one million stroke and transient ischemic attack admissions in get with the Guidelines-Stroke. Circ Cardiovasc Qual Outcomes 2010;3:291-302.

10 Feigin VL, Lawes CMM, Bennett DA, et al. Stroke epidemiology: a review of population-based studies of incidence, prevalence, and case-fatality in the late 20th century. Lancet Neurol 2003;2:43-53.

11 Heeley E, Anderson CS, Huang Y, et al. Role of health insurance in averting economic hardship in families after acute stroke in China. Stroke 2009;40:2149-56.

12 Ding D, Lu C-Z, Fu J-H, et al. Predictors of vascular events after ischemic stroke: the China ischemic stroke Registry study. Neuroepidemiology 2010;34:110-6.

13 Liu X, Xu G, Wu W, et al. Subtypes and one-year survival of first-ever stroke in Chinese patients: the Nanjing stroke Registry. Cerebrovasc Dis 2006;22:130-6.

$14 \mathrm{He} \mathrm{Q}$, Wu C, Luo H, et al. Trends in in-hospital mortality among patients with stroke in China. PLoS One 2014:9:e92763.

15 Li Z, Wang C, Zhao X, et al. Substantial progress yet significant opportunity for improvement in stroke care in China. Stroke 2016;47:2843-9.

16 Wang Y, Cui L, Ji X, et al. The China national stroke Registry for patients with acute cerebrovascular events: design, rationale, and baseline patient characteristics. Int J Stroke 2011;6:355-61.

17 Khan NA, Quan H, Hill MD, et al. Risk factors, quality of care and prognosis in South Asian, East Asian and white patients with stroke. BMC Neurol 2013;13:74.

18 Tsai C-F, Thomas B, Sudlow CLM. Epidemiology of stroke and its subtypes in Chinese vs white populations: a systematic review. Neurology 2013;81:264-72.

19 Wang Y, Li Z, Zhao X, et al. Stroke care quality in China: substantial improvement, and a huge challenge and opportunity. Int J Stroke 2017;12:229-35.
20 Wang Y, Li Z, Wang Y, et al. Chinese stroke center alliance: a national effort to improve healthcare quality for acute stroke and transient ischaemic attack: rationale, design and preliminary findings. Stroke Vasc Neurol 2018;3:256-62.

21 Tanne D, Koton S, Molshazki N, et al. Trends in management and outcome of hospitalized patients with acute stroke and transient ischemic attack: the National acute stroke Israeli (NASIS) registry. Stroke 2012;43:2136-41.

22 Stroke unit Trialists C. organised inpatient (stroke unit) care for stroke Cochrane database. Syst Rev 2013;9:CD000197.

23 Wang G, Fang B, Yu X, et al. [Interpretation of 2018 guidelines for the early management of patients with acute ischemic stroke]. Zhonghua Wei Zhong Bing Ji Jiu Yi Xue 2018;30:289-95.

24 Powers WJ, Rabinstein AA, Ackerson T, et al. Guidelines for the early management of patients with acute ischemic stroke: 2019 update to the 2018 guidelines for the early management of acute ischemic stroke: a guideline for healthcare professionals from the American heart Association/American stroke association. Stroke 2019;50:e344-418.

25 Appelros P, Jonsson F, Åsberg S, et al. Trends in stroke treatment and outcome between 1995 and 2010: observations from RiksStroke, the Swedish stroke register. Cerebrovasc Dis 2014;37:22-9.

26 Prvu Bettger JA, Kaltenbach L, Reeves MJ, et al. Assessing stroke patients for rehabilitation during the acute hospitalization: findings from the get with the Guidelines-Stroke program. Arch Phys Med Rehabil 2013;94:38-45.

27 Chen Y, Yin Z, Xie Q. Suggestions to ameliorate the inequity in urban/ rural allocation of healthcare resources in China. Int $J$ Equity Health 2014;13:34.

$28 \mathrm{Li} \mathrm{Z}$, Jiang $\mathrm{Y}, \mathrm{Li} \mathrm{H}$, et al. China's response to the rising stroke burden. BMJ 2019;364:1879.

29 Yu F, Liu X, Yang Q, et al. In-Hospital recurrence in a Chinese large cohort with acute ischemic stroke. Sci Rep 2019;9:14945.

30 Breuckmann F, Hochadel M, Grau AJ, et al. Quality benchmarks for chest pain units and stroke units in Germany. Herz 2020;69.

31 Reeves MJ, Arora S, Broderick JP, et al. Acute stroke care in the US: results from 4 pilot prototypes of the Paul Coverdell National acute stroke Registry. Stroke 2005;36:1232-40.

32 Bushnell CD, Olson DM, Zhao X, et al. Secondary preventive medication persistence and adherence 1 year after stroke. Neurology 2011;77:1182-90.

33 Zhang J, Gong Y, Zhao Y, et al. Post-Stroke medication adherence and persistence rates: a meta-analysis of observational studies. $J$ Neurol 2019;392. doi:10.1007/s00415-019-09660-y. [Epub ahead of print: 02 Dec 2019].

34 Hemphill JC, Greenberg SM, Anderson CS, et al. Guidelines for the management of spontaneous intracerebral hemorrhage: a guideline for healthcare professionals from the American heart Association/ American stroke association. Stroke 2015;46:2032-60.

35 Wei JW, Huang Y, Wang J-G, et al. Current management of intracerebral haemorrhage in China: a national, multi-centre, hospital register study. BMC Neurol 2011;11:16.

36 Yesilot N, Putaala J, Bahar SZ, et al. Ethnic and geographical differences in ischaemic stroke among young adults. Curr Vasc Pharmacol 2017;15:416-29.

37 Saposnik G, Hill MD, O'Donnell M, et al. Variables associated with 7-day, 30-day, and 1-year fatality after ischemic stroke. Stroke 2008;39:2318-24.

38 Niewada M, Kobayashi A, Sandercock PAG, et al. Influence of gender on baseline features and clinical outcomes among 17,370 patients with confirmed ischaemic stroke in the International stroke trial. Neuroepidemiology 2005;24:123-8.

39 Lavados PM, Sacks C, Prina L, et al. Incidence, 30-day casefatality rate, and prognosis of stroke in lquique, Chile: a 2-year community-based prospective study (piscis project). The Lancet 2005;365:2206-15

40 Feng W, Hendry RM, Adams RJ. Risk of recurrent stroke, myocardial infarction, or death in hospitalized stroke patients. Neurology 2010;74:588-93.

41 Wang $\mathrm{Y}$, Jing J, Meng $\mathrm{X}$, et al. The third China national stroke registry (CNSR-III) for patients with acute ischaemic stroke or transient ischaemic attack: design, rationale and baseline patient characteristics. Stroke Vasc Neurol 2019;4:158-64. 